\title{
Applicability of Modified Diercks Equation with NRIM Data
}

\author{
Tarun Goswami \\ Department of Mechanical Engineering, University of Utah, \\ Salt Lake City, UT 84112, USA
}

\begin{abstract}
The applicability of the modified Diercks equation (MDE) was assessed with elevated temperature low cycle fatigue (ETLCF) data generated by the National Research Institute for Metals (NRIM) for $1 \mathrm{Cr}-\mathrm{Mo}-\mathrm{V}$, $1.25 \mathrm{Cr}-\mathrm{Mo}, 2.25 \mathrm{Cr}-\mathrm{Mo}$ and $9 \mathrm{Cr}-1 \mathrm{Mo}$ steels respectively. The modified Diercks equation was assessed with data generated with symmetrical, slow-fast and hold-time waveforms for low alloy steels. The following characteristics were observed:

Symmetrical waveforms: Five strain rates were used with these waveforms where predicted life was by a factor of $\pm \times 2$ for $77 \%, 87 \%, 82 \%$ and $92 \%$ of data points for $1 \mathrm{Cr}-\mathrm{Mo}-\mathrm{V}, 1.25 \mathrm{Cr}-\mathrm{Mo}, 2.25 \mathrm{Cr}-\mathrm{Mo}$ and $9 \mathrm{Cr}-$ $1 \mathrm{Mo}$ steels respectively.

Slow-fast waveforms: Diercks equation was not applicable when the test parameters in tension and compression changed. However, when assessed with such data, predicted life was by a factor of \pm x2 for $93 \%, 66 \%$ and $66 \%$ of data for $1 \mathrm{Cr}-\mathrm{Mo}-\mathrm{V}, 2.25 \mathrm{Cr}-\mathrm{Mo}$ and $9 \mathrm{Cr}-1 \mathrm{Mo}$ steels respectively.

Holdtime waveforms: Tensile only holds of 0.1 and 1 hour were applied where the predicted life was by a factor of $\pm \times 2$ for $88 \%, 50 \%$ and $100 \%$ of test data for $1 \mathrm{Cr}-\mathrm{Mo}-\mathrm{V}, 2.25 \mathrm{Cr}-\mathrm{Mo}$ and $9 \mathrm{Cr}-1 \mathrm{Mo}$ steels respectively.
\end{abstract}

\section{INTRODUCTION}

Diercks equation /1/ as well as other statistical methods were widely explored $/ 2-8 /$ in Japan as an alternative tool in the creep-fatigue life prediction of low allow steels. There are many phenomenological methods of life prediction which, on analysis, prove to be no better than other methods. Hence, alternative methods for creep fatigue life prediction are currently being pursued. Historically, Diercks and Raskey /1/, in the Argonne National Laboratory, compiled a bank of creep-fatigue data on stainless steel of the type SS 304. They /1/ obtained a best-fit equation by fitting the data in terms of a multi-variate equation. Thus, Diercks equation contained several parameters with which the data were fitted in a multi-variate equation. The American Society of Mechanical Engineers /9/ recommended this equation for the construction of fatigue diagrams for SS 304 .

In this paper Diercks equation has been modified and its applicability assessed with a range of creepfatigue data that were generated by the NRIM. The applicability of Diercks equation was assessed with data on $1 \mathrm{Cr}-\mathrm{Mo}-\mathrm{V}, 1.25 \mathrm{Cr}-\mathrm{Mo}, 2.25 \mathrm{Cr}-\mathrm{Mo}$ and $9 \mathrm{Cr}-\mathrm{lMo}$ steels reported in NRIM Fatigue Data Sheet Nos. 58, 28,62 and 78 respectively $/ 10-13 /$. 


\section{DIERCKS' EQUATION}

Diercks equation /1/ in a multi-variate form was presented in regression functions in strain range, strain rate, temperature, and hold time parameters for creepfatigue life extrapolation of SS 304 , as follows:

$$
\begin{aligned}
\left.\left(\log \mathrm{N}_{\mathrm{f}}\right)\right)^{-1 / 2}= & 1.20551064+0.66002143 \mathrm{~S}+ \\
& 0.18040042 \mathrm{~S}^{2}-0.00814329 \mathrm{~S}^{4}+ \\
& 0.00025308 \mathrm{RS}^{4}+0.00021832 \mathrm{TS}^{4}- \\
& 0.00054660 \mathrm{RT}^{2}-0.005567 \mathrm{RH}^{2}- \\
& 0.00293919 \mathrm{HR}^{2}+0.0119714 \mathrm{HT}- \\
& 0.00051639 \mathrm{H}^{2} \mathrm{~T}^{2}
\end{aligned}
$$

where $S$ - a strain range parameter $\left(S=\Delta \varepsilon_{d} / 100\right), R$ - a strain rate parameter $(\mathrm{R}=\log \dot{\varepsilon}), \mathrm{T}$ - a temperature parameter $(T=T d 100)$, and $H$ - a hold time parameter $\left(\mathrm{H}=\log \left[1+\mathrm{t}_{\mathrm{h}}\right]\right), \Delta \varepsilon_{\mathrm{t}}$ is the \% total strain range, $\dot{\varepsilon}$ is the strain rate, $T_{c}$ is the test temperature of SS 304 and $t_{h}$ is the duration of hold time in hours, in the above equation.

Modifications were performed on the above equation by introducing a fatigue and a temperature correction factor by Kitagawa et al. $/ 2 /$, such that with the introduction of those terms in equation (1) the life predicted for SS 304 was scaled for a low alloy steel. Also, the modifications proposed in reference $/ 2 /$ required relative material properties of SS 304 and a low alloy steel under the same test conditions to establish the fatigue correction factor. It also required iso-stress creep rupture properties for the temperature correction factor. A limited number of creep-fatigue data for $2.25 \mathrm{Cr}-\mathrm{Mo}$ and $9 \mathrm{Cr}-1 \mathrm{Mo}$ were analyzed in reference $12 /$ where the prediction was found by a factor of two.

In practice, the material data for SS 304 and low alloy steels are quite meager for the purpose of establishing the correction factors. Hence, a simpler modification was needed to make this equation applicable for a wide range of conditions and low alloy steels. A cycle time factor and a material dependent equivalent strain rate term were introduced to modify Diercks equation. These were determined for every low alloy steel using the data fitting techniques and by trial and error methods, by fitting a selected set of data. Later, these terms were fixed for each low alloy steel and life assessment was performed. The modifications were proposed mainly because of the lack of strain rates and other test details in the published literature to generalize the equation.

\section{MODIFICATION OF DIERCKS EQUATION}

\section{Introduction of a cycle time $(\tau)$ factor}

Owing to the limitations discussed above and the advantages of this equation, a modification was made to apply this method where no details of relative fatigue and iso-stress creep rupture properties were available. A cycle time parameter $(\tau)$, which is a ratio of total strain parameter $(S),\left(\Delta \varepsilon_{t} / 100\right)$, with strain rate $(\% / \mathrm{sec})$ was introduced. The equation in a modified form, if the right hand side of the equation (1) remained the same, was proposed below:

$$
\left[\log (\tau \mathrm{N} f)^{-1 / 2}\right]=\text { RHS of equatiton (1) }
$$

Using equation (2), the life of various low alloy steels under creep-fatigue was found to be the same, if at the same strain range, temperature and hold time the strain rate parameter was equivalent. Hence, to apply this equation for a range of low alloy steels, a material dependent equivalent strain rate $\left(\varepsilon_{\mathrm{e}}\right)$, was introduced.

The modification made by Kitagawa et al. /2/ also involved a temperature correction factor, which scaled the creep rupture properties of SS 304 with respect to low alloy steel. Kitagawa et al. /2/ found that the isostress creep rupture properties of low alloy steels ranged from 50 to $100^{\circ} \mathrm{C}$ lower than the creep rupture properties of SS 304. With the introduction of the temperature correction factor from reference $/ 2 /$, creepfatigue response of low alloy steels did not change considerably (from 10-15 cycles) when assessed with modified equation (2). The temperature correction factor was therefore assumed to be the same as in reference $/ 2 /$, with the same factor of $100^{\circ} \mathrm{C}$ for all low alloy steels.

\section{Material Dependent Equivalent Strain Rate $\left(\dot{\varepsilon}_{\mathrm{e}}\right)$}

The material dependent equivalent strain rate (MDESR) was determined by a method of trial and 
error, as follows:

1. obtain a total strain versus life extrapolation equation by fitting a few creep-fatigue data points with different $\dot{\varepsilon}$, hold times and temperatures in terms of:

$$
\Delta \varepsilon_{\mathrm{l}}=\mathrm{A}\left(\mathrm{N}_{\mathrm{f}}\right)^{-\beta}
$$

2. determine the parameters (A and $-\beta$ ) of the total strain versus life best fit equation (3), that was used to generate a response curve for an average behavior,

3. extrapolate this equation at several strain levels,

4. use equation (2) with several assumed values of material dependent equivalent strain rates by a trial and error method probabilistically (it ranged from 0.05 to 0.5 for most materials),

5. select the value of the material dependent equivalent strain rate $\left(\varepsilon_{e}\right)$, when there is a good degree of fit between the extrapolated life and that predicted by equation (2).

Choices can be made between the most conservative and over-predicted responses. The material dependent equivalent strain rate varied from data to data as the parameters of the extrapolated equation changed with the creep-fatigue test types. From a large number of low alloy steels studied in a separate study $/ 14 /$, in normalized and tempered conditions (N\&T), the material dependent equivalent strain rate ranged from 0.1 to 0.5 , which were kept 'constant' for each low alloy steel grade for the sake of simplicity. However, one value of material dependent equivalent strain rate will be very conservative for one type of creep-fatigue sequence with a particular hold direction, but may over-predict for the other holds. Under N\&T conditions, the rates of 0.1 for $0.5 \mathrm{Cr}-\mathrm{Mo}-\mathrm{V}$ and $1 \mathrm{Cr}-\mathrm{Mo}-\mathrm{V}, 0.25$ for $1.25 \mathrm{Cr}-\mathrm{Mo}$ and $0.5 \% / \mathrm{sec}$. for $2.25 \mathrm{Cr}-\mathrm{Mo}, 2.25 \mathrm{Cr}-\mathrm{Mo}-\mathrm{V}$ and $9 \mathrm{Cr}-1 \mathrm{Mo}$ steels, were obtained /14/. These values were kept the same for all combinations of hold times and strain ranges for the above grades of low alloy steels, assessed in reference /14/. However, with the NRIM data, these parameters were 0.1 for $1 \mathrm{Cr}-\mathrm{Mo}-\mathrm{V}$ steel under N\&T conditions and were determined in the hot rolled condition for $1.25 \mathrm{Cr}-\mathrm{Mo}, 2.25 \mathrm{Cr}-\mathrm{Mo}$ and $9 \mathrm{Cr}-1 \mathrm{Mo}$ steels as $0.25,0.15$ and 0.15 respectively. Figure 1 describes the fit between the extrapolated behavior (drawn with data) with the life predicted by equation (2), with different values of material dependent equivalent strain rate $\left(\varepsilon_{\mathrm{e}}\right)$. Further derivatives of the material dependent equivalent strain rate should be derived depending upon the individual material condition, composition, and the form of the materials by the method described in the five stages. Also, this parameter determined for a material under a particular condition was valid only under those conditions.

\section{Demerits}

A few relevant limitations of the modified method are that:

- equations (1) and (2) only consider hold periods in which they are more damaging, which is either tension or compression for the balanced cycles,

- the modified equation applies to the prediction of life only below 10,000 cycles,

- the modified equation applies above plastic strain range greater than elastic strain range, and

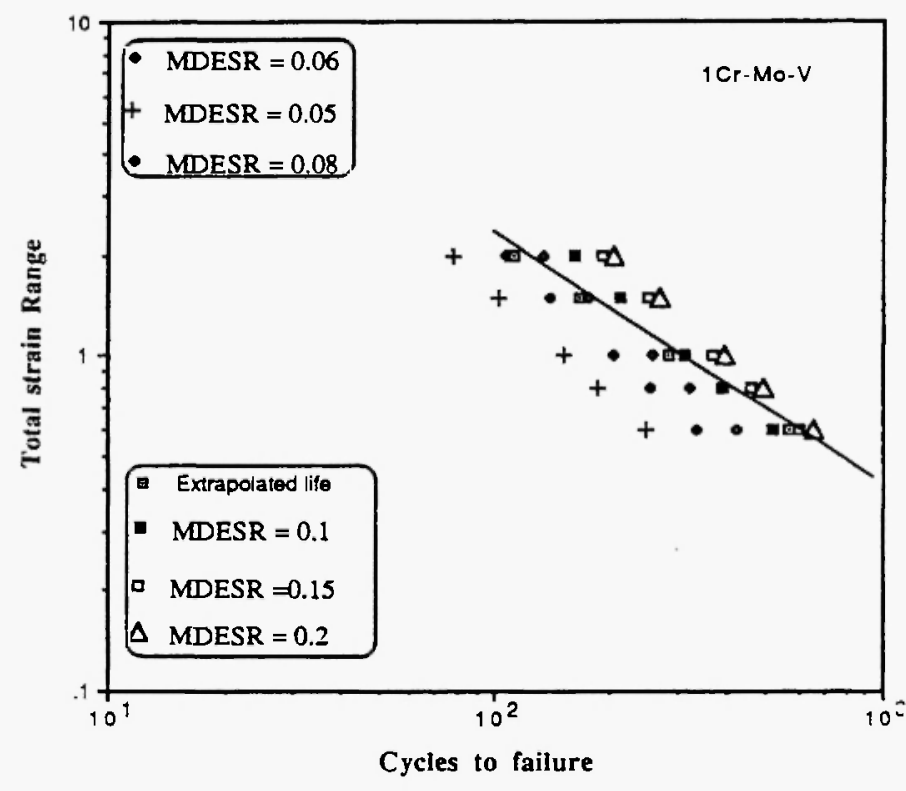

Fig. 1: Determination of material dependent equivalent strain rate for $1 \mathrm{Cr}-\mathrm{Mo}-\mathrm{V}$ steel. 
- the effects of strain rate and waveforms are considered fixed in one predominating direction.

\section{NRIM MATERIALS AND CREEP-FATIGUE TEST MATRICES}

Four low alloy steels, namely $1 \mathrm{Cr}-\mathrm{Mo}-\mathrm{V}, 1.25 \mathrm{Cr}-$ Mo, $2.25 \mathrm{Cr}$-Mo and $9 \mathrm{Cr}$-1Mo were analyzed in this paper. The chemical composition, heat treatment condition and type of tests used for different materials are described in Tables 1 through 3 , respectively.

The test matrix for $1.25 \mathrm{Cr}$-Mo steel was different from the other three materials. Only symmetrical waveforms were investigated for $1.25 \mathrm{Cr}-\mathrm{Mo}$ steel with strain rates from $0.1 \% / \mathrm{sec}$. to $0.001 \% / \mathrm{sec}$. However, for other materials symmetrical, slow-fast and tensile hold time waveforms were used. Table 3 provides a detailed matrix of test parameters employed by NRIM /13/.

\section{DISCUSSION ON THE APPLICABILITY OF THE MODIFIED EQUATION}

The modified equation was assessed with creepfatigue data which were generated for room temperature to $650^{\circ} \mathrm{C}$ for different materials and are discussed below according to the higher order of chromium content:

\section{Cr-Mo-V Steel}

Symmetrical waveforms: The tests contained symmetrical waveforms as shown in Table 3, with several temperature and strain rate combinations. The rate of change of strain with respect to time, strain rate, is very decisive in the performance of materials under creep-fatigue testing. It is imperative to expect life debits with lower strain rates. The predicted life of $1 \mathrm{Cr}$ $\mathrm{Mo}-\mathrm{V}$ steel under symmetrical waveform is shown in Fig. 2. Seventy-seven percent of test data points were predicted by a factor of $\pm \times 2$. The life prediction was conservative for $100 \%$ of test data points where lives of higher strain rates, e.g. $0.5 \% / \mathrm{sec}$ and $0.1 \% / \mathrm{sec}$, were under-predicted when the experimental life was near to or higher than 1,000 cycles.

Slow-fast waveforms: Four combinations of test parameters were investigated by NRIM /10/. The strain rate varied in the tension and compression directions. All the data points were predicted conservatively in

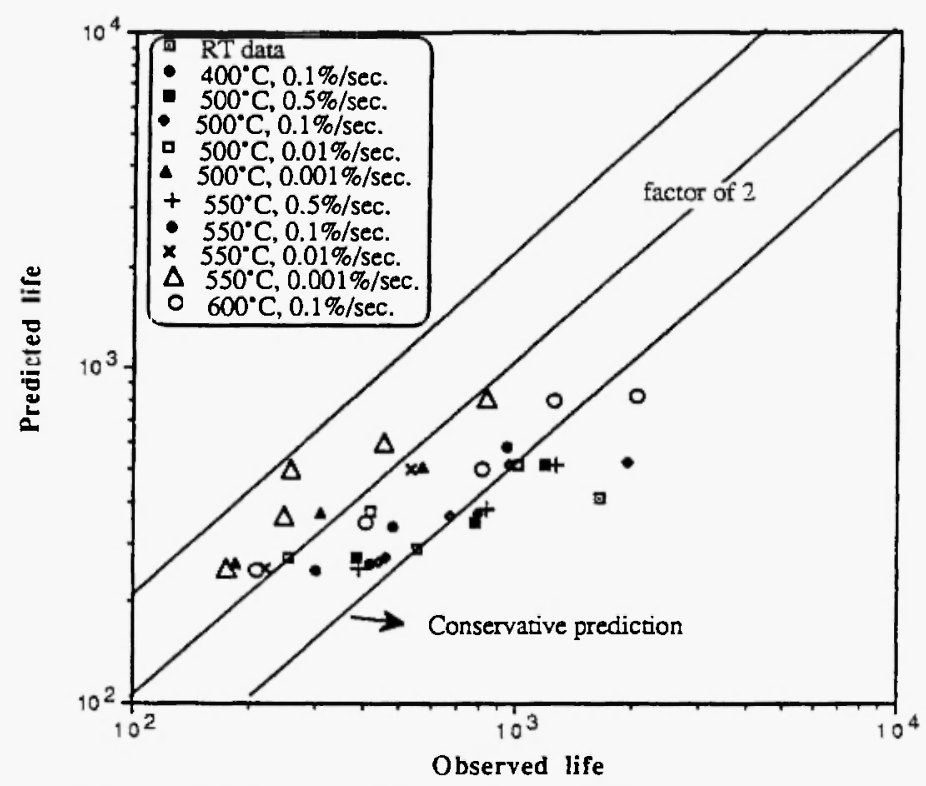

Fig. 2: Life prediction of $1 \mathrm{Cr}-\mathrm{Mo}-\mathrm{V}$ steel under symmetrical waveforms.

Table 1

Chemical composition of materials investigated /10-13/

\begin{tabular}{|l|c|c|c|c|c|c|c|c|c|c|c|c|}
\hline \multicolumn{1}{|c|}{ Matcrial } & $\mathbf{C}$ & $\mathbf{S i}$ & $\mathbf{M n}$ & $\mathbf{P}$ & $\mathrm{S}$ & $\mathrm{Ni}$ & $\mathbf{C r}$ & $\mathbf{M o}$ & $\mathbf{C u}$ & $\mathbf{V}$ & $\mathbf{S b}$ & $\mathbf{N}$ \\
\hline $1 \mathrm{Cr}-\mathrm{Mo}-\mathrm{V}^{\mathrm{y}}$ & .29 & .3 & .74 & .006 & .003 & .39 & 1.12 & 1.16 & .03 & .25 & .002 & .004 \\
\hline $1.25 \mathrm{Cr}-\mathrm{Mo}^{\mathrm{b}}$ & .15 & .62 & .53 & .007 & .007 & .15 & 1.16 & .52 & .07 & & & .013 \\
\hline $2.25 \mathrm{Cr}-\mathrm{Mo}^{\mathrm{b}}$ & .13 & .02 & .50 & .007 & .009 & .16 & 2.43 & .96 & .07 & & & .007 \\
\hline $9 \mathrm{Cr}-1 \mathrm{Mo}^{\mathrm{b}}$ & .08 & .34 & .49 & .005 & .004 & .09 & 8.34 & .89 & .02 & .23 & & .059 \\
\hline
\end{tabular}

(where $\mathrm{a}$ and $\mathrm{b}$ are forged under N\&T and plate in hot rolled conditions respectively.) 
Table 2

Details of the material condition and production histories ${ }^{10-13)}$.

\begin{tabular}{|c|c|c|c|c|}
\hline Material & Product form & Reduction ratio & Thermal history & $\begin{array}{l}\text { Austenitic grain } \\
\text { size }\end{array}$ \\
\hline $1 \mathrm{Cr}-\mathrm{Mo}-\mathrm{V}$ & Forging & 3.2 & $\begin{array}{l}1010^{\circ} \mathrm{C} / 24 \mathrm{~h} \text { ac } \\
700^{\circ} \mathrm{C} / 38 \mathrm{~h} \mathrm{ac} \\
650 / 5 \mathrm{~h}-955^{\circ} \mathrm{C} / \\
19 \mathrm{~h} \mathrm{ac}, 680^{\circ} \mathrm{C} / \\
38 \mathrm{~h} \mathrm{fc} .\end{array}$ & $\begin{array}{l}7.5 \\
\text { following } \\
\text { JIS G } 0.551 \\
(1977) .\end{array}$ \\
\hline $1.25 \mathrm{Cr}-\mathrm{Mo}$ & Plate, hot rolled & 39.1 & $\begin{array}{l}925^{\circ} \mathrm{C} / 50 \mathrm{~min} . \mathrm{ac} \\
690^{\circ} \mathrm{C} / 60 \mathrm{~min} . \mathrm{ac} \\
655^{\circ} \mathrm{C} / 60 \mathrm{~min} . \mathrm{fc}\end{array}$ & $\begin{array}{l}8.0 \text { following } \\
\text { JIS G } 0.551 \\
\text { (1977). } \\
\end{array}$ \\
\hline $2.25 \mathrm{Cr}-\mathrm{Mo}$ & Plate, hot rolled & 23 & $\begin{array}{l}920^{\circ} \mathrm{C} / 1.3 \mathrm{~h} \mathrm{ac}, \\
670^{\circ} \mathrm{C} / 2.3 \mathrm{~h} \mathrm{ac}, \\
650^{\circ} \mathrm{C} / 10.3 \mathrm{~h} \mathrm{fc}\end{array}$ & $\begin{array}{l}5.5 \text { following } \\
\text { JIS . G } 0.551 \\
(1977) . \\
\end{array}$ \\
\hline $9 \mathrm{Cr}-1 \mathrm{Mo}$ & Plate, hot rolled & 8 & $\begin{array}{l}1050^{\circ} \mathrm{C} / 10 \mathrm{~min} \\
\text { ac, } 770^{\circ} \mathrm{C} / 1 \mathrm{~h} \mathrm{ac} \\
740^{\circ} \mathrm{C} / 1 \mathrm{~h} \mathrm{fc}\end{array}$ & $\begin{array}{l}11.6 \text { following } \\
\text { JIS G } 0.551 \\
(1977) \text {. }\end{array}$ \\
\hline
\end{tabular}

(where ac for air cooling and fc for furnace cooling respectively)

Fig. 3 where $93 \%$ of test data was predicted by a factor of $\pm \mathrm{x} 2$.

Tensile hold-time waveforms: Prediction of all the data points was conservative where $88 \%$ of test data points were predicted by a factor of $\pm \times 2$ in Fig. 4 . The over-predicted point in Fig. 4 was under the condition of $500^{\circ} \mathrm{C}, 0.5 \% / \mathrm{sec}, 1 \mathrm{hr}$. hold at $0.3 \%$ total strain range. It is interesting to note the life at $0.3 \%$ total strain range was $1 / 2$ the life at $1 \%$ and $0.82 \%$ and $1 / 4$ of $0.5 \%$ total strain ranges. Therefore, all the data were predicted conservatively by the modified Diercks' equation.

\subsection{Cr-Mo Steel}

Symmetrical waveforms: Only symmetrical waveforms were employed in the ETLCF testing of this material. Life prediction by the modified Diercks

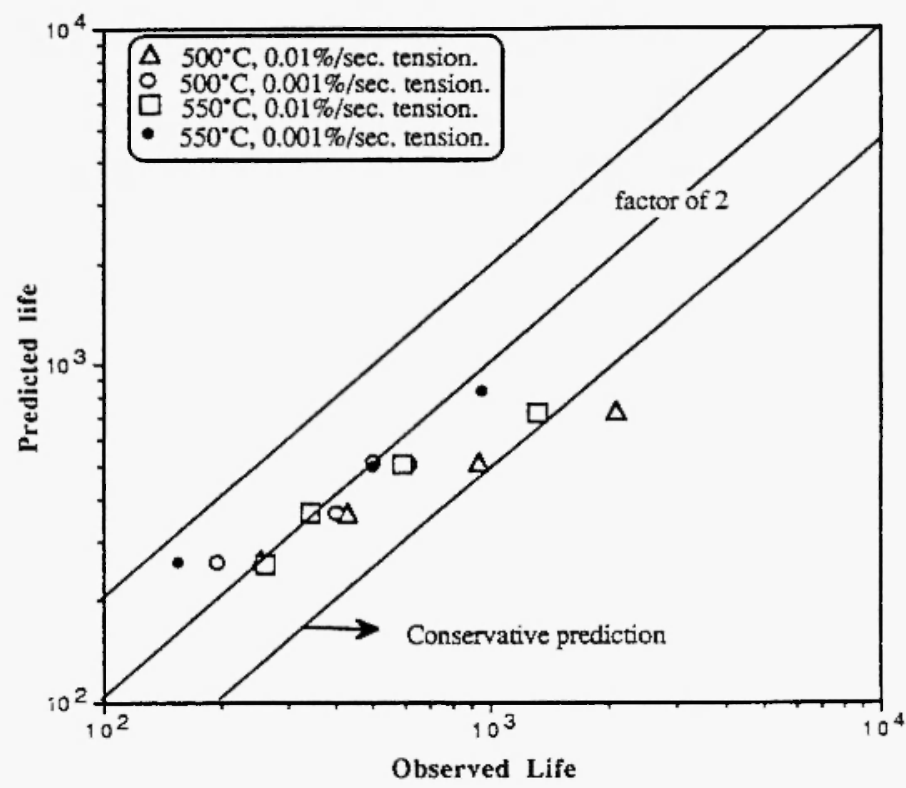

Fig. 3: Life prediction of $1 \mathrm{Cr}-\mathrm{Mo}-\mathrm{V}$ steel under slow-fast waveforms. 
Table 3

Details of the test matrix employed for different materials by NRIM ${ }^{13)}$.

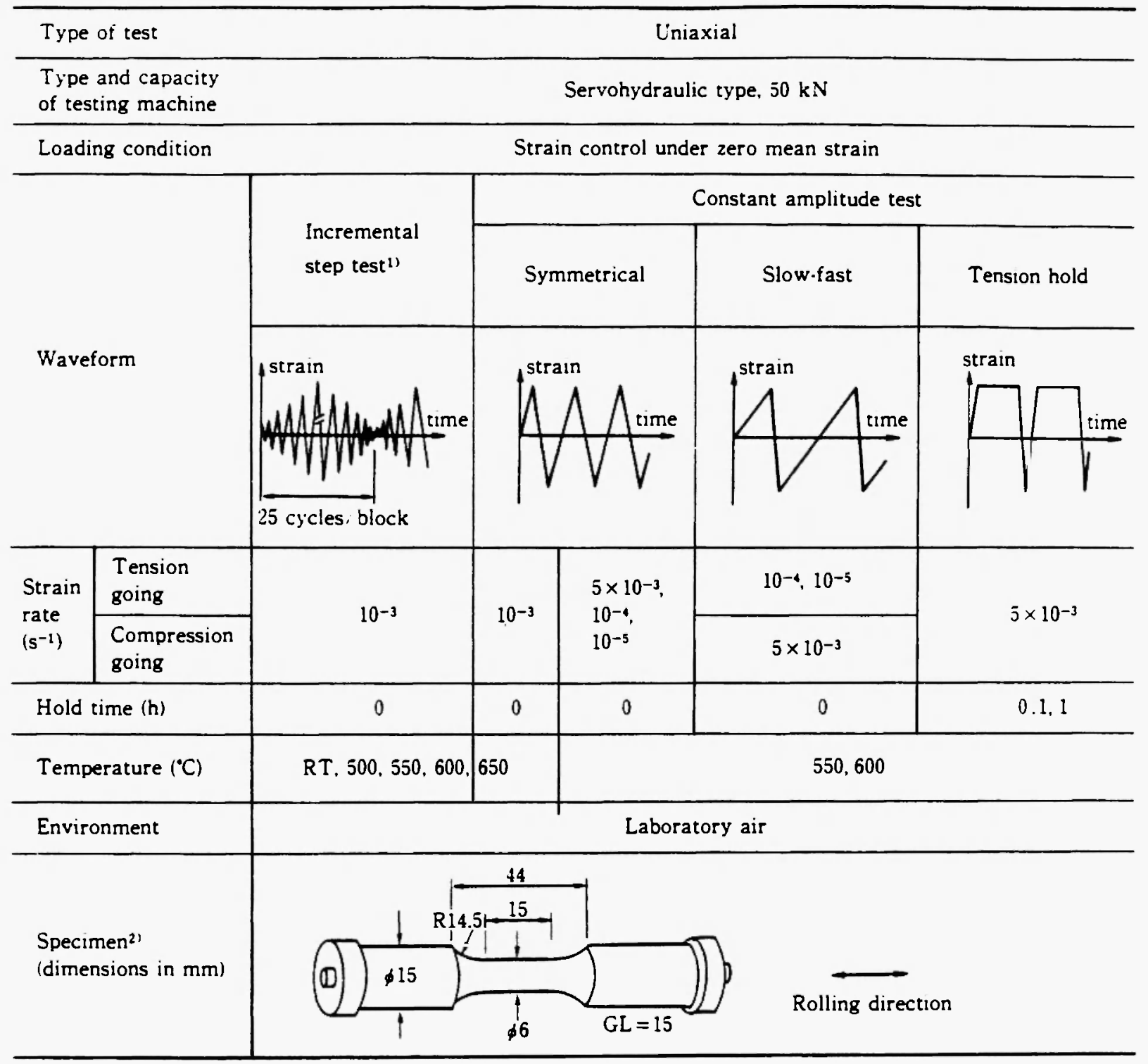

equation was found to be conservative for all the data. Eighty seven percent of test data points with five temperatures and three strain rates were predicted by a factor of $\pm x 2$ in Fig. 5. The life of a $600^{\circ} \mathrm{C}$, $0.001 \% / \mathrm{sec}$ strain rate test at $1.9 \%$ total strain range was over-predicted by a factor of 3 in Fig. 5.

Such a discrepancy is due mainly to a lower strain rate employed in testing than the modified Diercks equation considered in the determination of material dependent equivalent strain rate term, which was kept constant for all types of creep-fatigue tests. Thus, the predicted life was higher than the experimentally observed life.

\subsection{Cr-Mo Steel}

Symmetrical waveforms: Combinations of five temperatures and four strain rates were assessed with the modified Diercks equation. Since the data contained a wide range of test parameters, the scatter in the predicted life was higher as a result. Eighty two percent of test data points were predicted by a factor of $\pm x 2$ in 


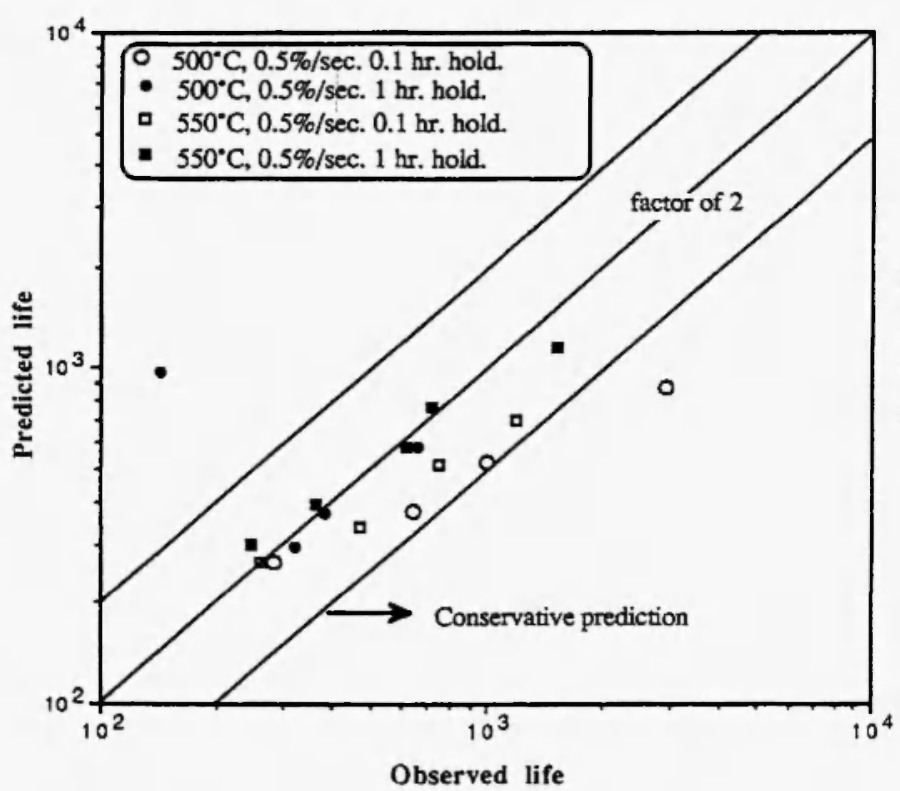

Fig. 4: Life prediction of $1 \mathrm{Cr}-\mathrm{Mo}-\mathrm{V}$ steel under hold time waveforms.

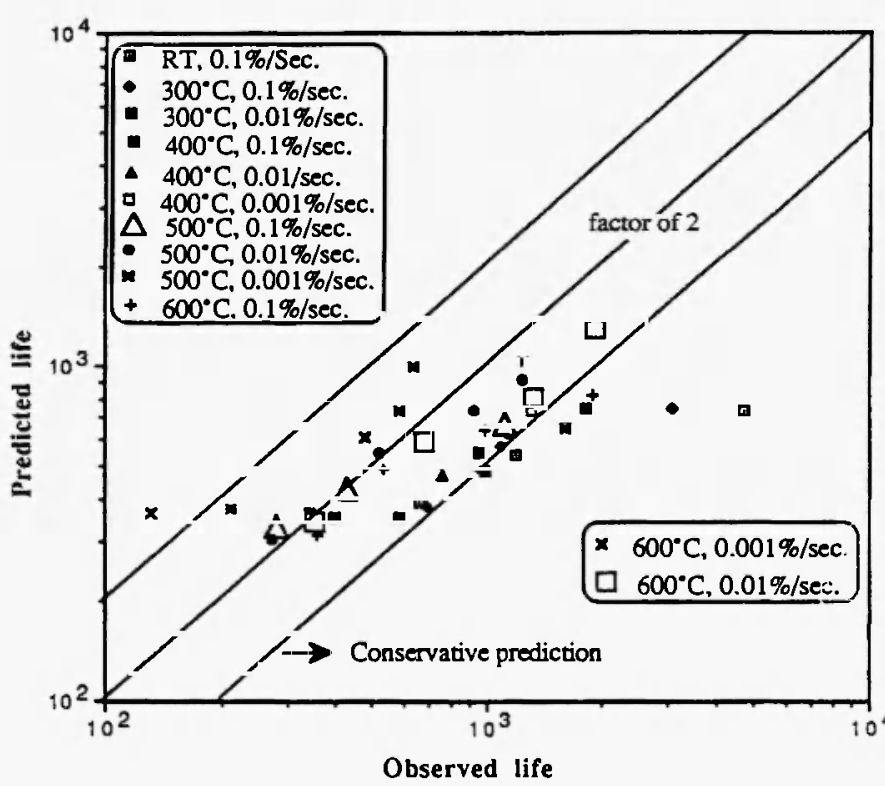

Fig. 5: Life prediction of $1.25 \mathrm{Cr}-\mathrm{Mo}$ steel under symmetrical waveforms.

Fig. 6, except for the lower strain rate-higher temperature combination (e.g. $600^{\circ} \mathrm{C}, 0.001 \% / \mathrm{sec}$ ) that was over-predicted by a factor of 3 . However, higher strain rate-lower temperature combinations (e.g. RT, $0.1 \% / \mathrm{sec}$ and $300^{\circ} \mathrm{C}, 0.1 \% / \mathrm{sec}$ ) were under-predicted by a factor of 3 . Therefore, life prediction was found to

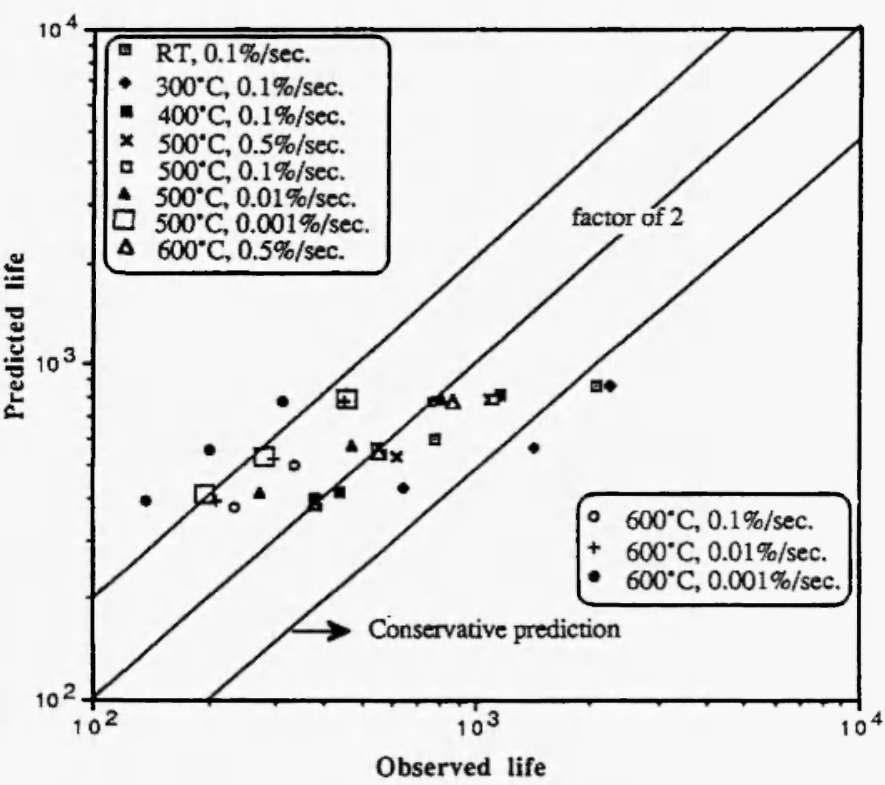

Fig. 6: Life prediction of $2.25 \mathrm{Cr}-\mathrm{Mo}$ steel under symmetrical waveforms.

be very good for $2.25 \mathrm{Cr}$-Mo steel under symmetrical waveforms.

Slow-fast waveforms: Only $66 \%$ of tests were predicted by a factor of $\pm x 2$ in Fig. 7. In those tests with combinations of higher temperatures-lower strain rates

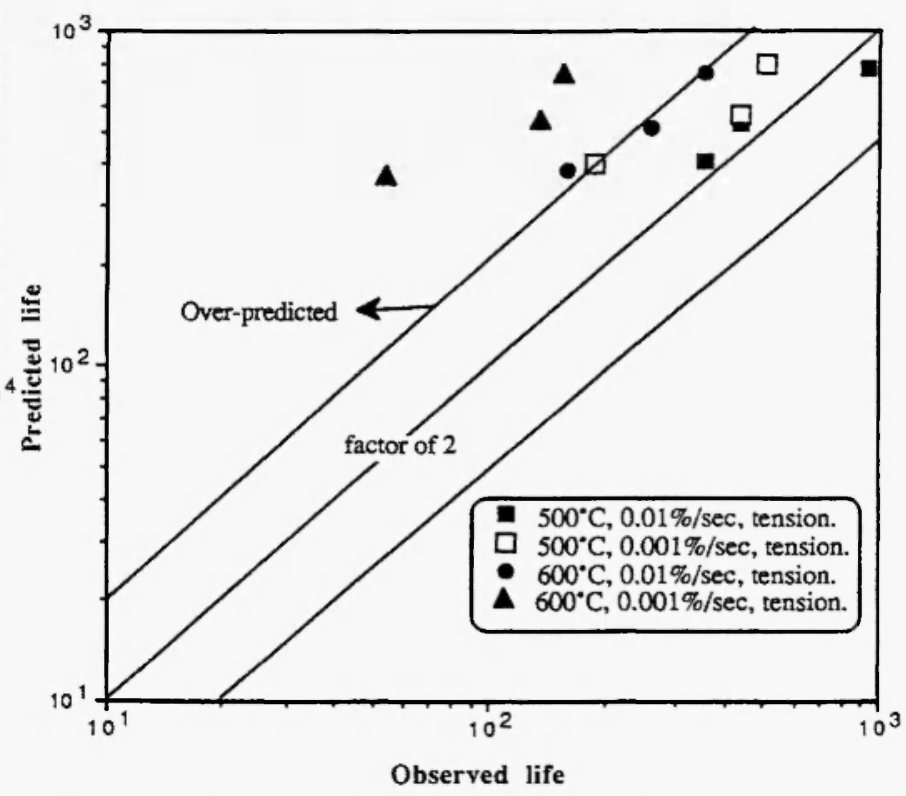

Fig. 7: Life prediction of $2.25 \mathrm{Cr}$-Mo steel under slow-fast waveforms. 
(e.g. $600^{\circ} \mathrm{C}, 0.001 \% / \mathrm{sec}$ tension) the life was overpredicted by a factor of 7 or more. Hence, this method was unsatisfactory in the creep-fatigue life prediction of $2.25 \mathrm{Cr}$-Mo steel with slow-fast waveforms where tensile and compressive strain rates changed with time.

Tensile hold-time waveforms: Only $50 \%$ of test data points were predicted by a factor of $\pm x 2$ in Fig. 8 . Tests with $0.1 \mathrm{hr}$ hold at $500^{\circ} \mathrm{C}$ with $0.5 \% / \mathrm{sec}$ strain rates were predicted by a factor of $\pm x 2$. However, other tests were over-predicted.

\section{Cr-1Mo Steel}

Symmetrical waveforms: Prediction of all the data by MDE was conservative where $92 \%$ of test data points were predicted by a factor of $\pm x 2$. Five temperatures and four strain rates were predicted in Fig. 9. Higher strain rate tests at lower temperatures, i.e., room and $500^{\circ} \mathrm{C}$, were under-predicted by a factor from 3 to 4.

Slow-fast waveforms: thirty three percent of test data points which contained $0.001 \% / \mathrm{sec}$ strain rates at $550^{\circ} \mathrm{C}$ and $600^{\circ} \mathrm{C}$ were over-predicted by a factor from 3 to 4 , as shown in Fig. 10.

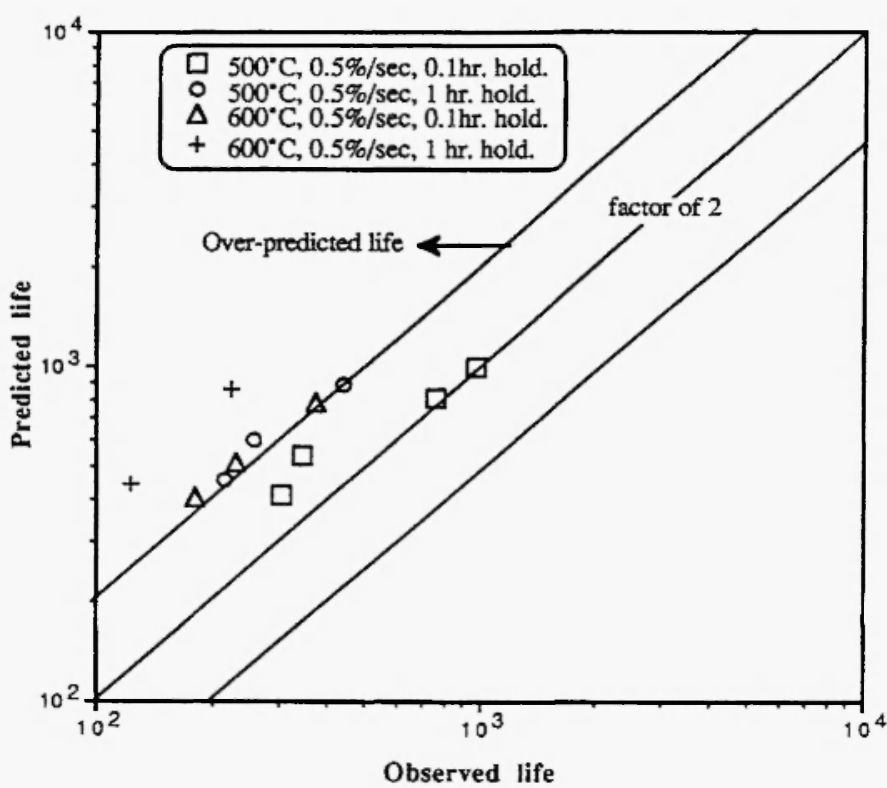

Fig. 8: Life prediction of $2.25 \mathrm{Cr}$-Mo steel under hold time waveforms.

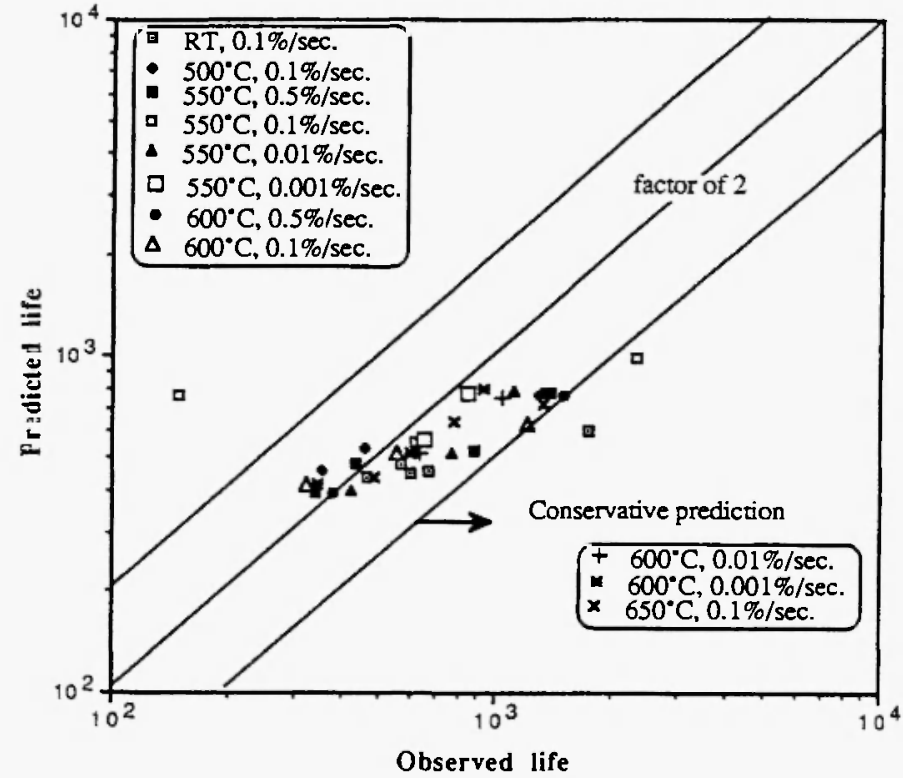

Fig. 9: Life prediction of 9Cr-lMo steel under symmetrical waveforms.

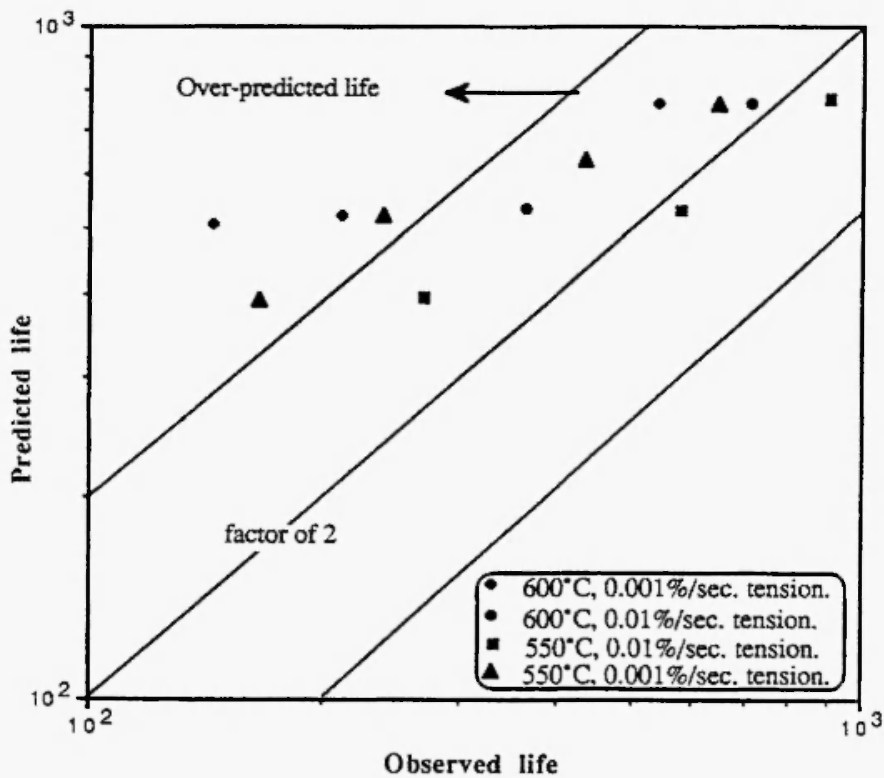

Fig. 10: Life prediction of $9 \mathrm{Cr}-1 \mathrm{Mo}$ steel under slowfast waveforms.

Tensile hold-time waveforms: All the test data points were predicted by a factor of $\pm x 2$.

From the analysis performed above, it is evident that life was predicted by a factor of 2 for most cases. 


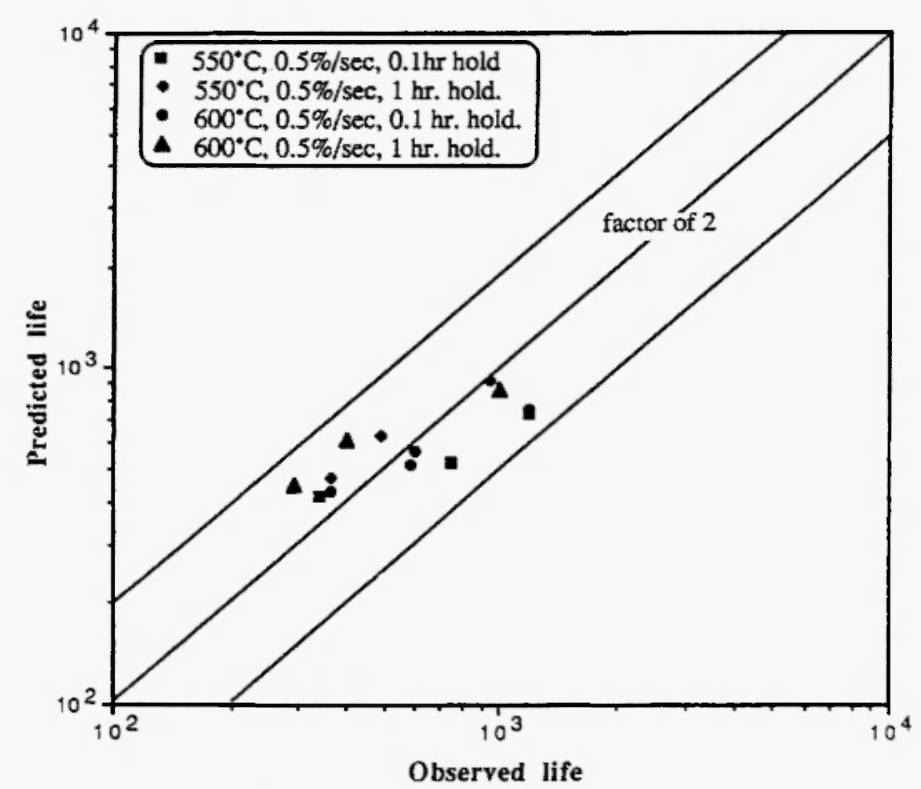

Fig. 11: Life prediction of $9 \mathrm{Cr}-1 \mathrm{Mo}$ steel under hold time waveforms.

Other phenomenological methods of life prediction are also applicable specific to a data type and test parameters. The hold time cycles in both tension and compression directions were treated as hold in one direction, where a longer hold time was applied on the assumption that the "damage" in the tension and/or compression directions was the same. Similarly, the relaxation of stresses with the application of hold time was assumed to have the same rate in the tension and compression directions respectively. The modified Diercks' equation does not require the details of the tests and mechanistic observations related to the "damage" and its growth. This equation was applicable only for those cases where the test parameters did not change during a cycle. The hold time cycles were analyzed with respect to the application of hold in one direction. The strain rates were not specified in open literature and modifications proposed in this paper aim to address those cases. The material dependent equivalent strain rate term should be determined from appropriate data fitting that may change when a range of strain rates such as NRIM data that are examined in this paper have been assessed. Despite these disadvantages, there is a potential for this method in the creep-fatigue life prediction of low alloy steels as more data points were predicted by a factor of $\pm \times 2$. Further work needs to be undertaken jointly with other workers that may benefit in modifying this method using the statistical probabilistic concepts for a range of data and in recommending the use of this equation in creepfatigue life prediction.

\section{CONCLUSIONS}

The life prediction of low alloy steels was found to be satisfactory using the modified Diercks equation. The following observations were made:

1. Under symmetrical waveforms at least $77 \%$ of test data points were predicted by a factor of $\pm \times 2$ for $1 \mathrm{Cr}-\mathrm{Mo}-\mathrm{V}$ steel. For other materials it was $87 \%$, $82 \%$ and $92 \%$ of data points for $1.25 \mathrm{Cr}-\mathrm{Mo}$, $2.25 \mathrm{Cr}-\mathrm{Mo}$ and $9-\mathrm{Cr}$-1Mo steels respectively.

2. Under slow-fast waveforms at least $66 \%$ of test data points were predicted by a factor of $\pm \mathrm{x} 2$ for $2.25 \mathrm{Cr}$ Mo steel. In the case of $1 \mathrm{Cr}-\mathrm{Mo}-\mathrm{V}$ steel, $93 \%$ of test data points were predicted by a factor of $\pm \mathrm{x} 2$.

3. Under hold time waveforms at least $50 \%$ of test data points were predicted by a factor of $\pm \times 2$ for $2.25 \mathrm{Cr}$ Mo steel. However, $100 \%$ of test data points were predicted by a factor of $\pm \times 2$ for $9 \mathrm{Cr}-1 \mathrm{Mo}$ steel.

4. The material dependent equivalent strain rate term was assumed to be constant for the entire data types of the same low alloy steel. However, if appropriate data fitting is conducted for various test parameters, this value may change and enhance the prediction capability of the equation. This may require more test data.

\section{ACKNOWLEDGEMENTS}

The authors would like to thank the National Research Institute for Metals, Tokyo, Japan and Dr. K. Yamaguchi for the provision of creep-fatigue data and interests in the analysis. Dr. M. Kitagawa from I.H.I. Co. provided the first insights on the subject of this paper and its scope. The support provided by Professors D.W. Hoeppner and W.J. Plumbridge is acknowledged. 


\section{REFERENCES}

1. D.R. Diercks and D.T. Raskey, ASME Annual Winter Meeting, 33 (1976).

2. K. Sonoya, I. Nonaka and M. Kitagawa, ISIJ International, 31 (12), 1424 (1991).

3. M. Kitagawa, I. Nonaka and K. Sonoya, Fatigue, 90 (III), 1537 (1990).

4. Y. Wada, Y. Kawakami and K. Aoto, in: Thermal Stress, Material Deformation and ThermoMechanical Fatigue, Vol. 123, H. Sehitoglu and S.Y. Zamrik (eds.), PVP, 1987; p. 37.

5. K. Aoto, Y. Wada and R. Komine, in: Thermal Stress, Material Deformation and ThermoMechanical Fatigue, Vol. 123, H. Sehitoglu and
S.Y. Zamrik (eds.), PVP, 1987; p. 43.

6. M. Kitagawa, private discussion (1992).

7. K. Yamaguchi, K. Kobayashi, K. Ijima and S. Nishijima, ASME J. Eng. Mater. and Struct. , in print (1994).

8. S. Taira, M. Fujino and R. Ohtani, Fatigue of Engng. Mater. Struct., 1, 495 (1979).

9. ASME Boiler and Pressure Vessel Code, Section III, Case N-47-23 (1986).

10. NRIM Fatigue Data Sheet No. 58 (1987).

11. NRIM Fatigue Data Sheet No. 28 (1981).

12. NRIM Fatigue Data Sheet No. 62 (1989).

13. NRIM Fatigue Data Sheet No. 78 (1993).

14. T. Goswami, Int. J. High Temp. Materials \& Processes, Paper III, 1995. 